District Health Authority. Sadly, despite his commitment and the health authority's grudging agreement to an alcohol policy, sale of alcohol in medical school buildings in this district continues to expand. The opening of the new education unit with a superfluity of alcohol added one more access point for cheap alcohol for the medical school and health authority staff.

FEDELMA WINKLER City and Hackney Community Health Council, London E2 8EB

\section{How can good general practitioner care be achieved?}

SIR,-Professor D C Morrell and Dr M O Roland have produced good reasons to suggest that good quality practice requires a reduction in average list size to no more than 1750 (17 January, p 161). They further suggest that in deprived inner city areas a list size of 1500 may be too many, and effective list size should probably be smaller.

If they are right, and I believe they are, there are serious implications for GP training because under the current regulations a trainer in an urban area should normally have not fewer than 2000 patients on his or her list (red book section 38.5/f). In practice this seems to mean an average list size of 2000 for the practice as a whole, and I understand that in some training practices the average may be nearer 3000 , nearly twice the number of patients that Professor Morrell and Dr Roland feel can be given good quality care. As trainees are supposed to be supernumary and as training practices should be able to function normally when the trainee is absent, there seems to be a paradox: training practices, particularly in inner cities, cannot give good quality care or show it to trainees, and good quality practices with small lists cannot take on trainees.

The profession has for some time accepted that average lists must come down to around 1700 . The time has come to review the acceptable number of patients for a training practice. This must include a maximum number as well as a minimum, as it is clearly wrong for trainers to be encouraged to have higher than ideal lists.

Bristol 2

PETER GodFrey

SIR,-As Professor D C Morrell and Dr M O Roland point out, there is an emerging consensus from general practice that an average consultation length of 10 minutes or more is needed and some evidence that longer consultations are associated with beneficial outcomes. There are difficulties, however, in using this evidence to make recommendations about list size. Two recent studies have shown only weak associations between average consultation length and list size ${ }^{12}$; it seems that the list size is associated more with consultation rate than consultation length. ${ }^{3}$

The problem with such observational studies is that we do not know which of these variables is dependent on the other. Doctors with low consultation rates (determined by demographic and possibly practice factors) might have chosen to use the extra time to increase their list size. Alternatively, practices with large lists might force a low consultation rate on their patients by lack of availability.

A recent study of training practices found that scores for preventive activity were higher in practices with lower list sizes. ${ }^{4}$ Interestingly, practices with formal screening programmes rather than a policy of case finding in the consultation achieved the best results. Specific clinics rather than extended consultations might be a better use of any time made available by lower list size.

Department of General Practice,

ANDREW WILSON

Queen's Medical Centre,

Nottingham NG7 2UH

1 Wilson AD. Consultation length: general practitioners' attitudes and practices. BrMed f 1985;290:1322-4.

2 Knight R. The importance of list size and consultation length on factors in general practice. $\mathcal{J} R$ Coll Gen Pract 1987;37:19-22. 3 Butler JR. How many patients? A study of list sizes in general practice. London: Bedford Square Press, 1980. (Occasiona papers in social administration No 64 .)

4 Fleming DM, Lawrence MSTA, Cross KW. List size screening methods and other characteristics of practices in relation to preventive care. Br Med f 1985;291:869-72.

Why women are not receiving anti-Rh prophylaxis

SIR,-Dr Ruth M Hussey (10 January, p 119) claims that the number of $\mathrm{Rh}$ negative mothers who developed $\mathrm{Rh}$ antibodies because they failed to receive an injection of anti-D immunoglobulin in the Liverpool region was less than that reported from the Yorkshire region, ${ }^{1}$ particularly when the failure of administration was after an abortion. However, more recent data (table) reveal less of a discrepancy. Failures of administration in 1985 were only $13 \%$ of the new cases compared with Liverpool's $7 \%$. It must also be noted that in $28 \%$ of Dr Hussey's series the cause of the sensitisation was unknown. Thus the Liverpool results are similar to those of Yorkshire. This is reinforced by almost identical incidences of antibodies developing in primigravidas (14\% in Liverpool and $18 \%$ in Yorkshire) and in failure of protection ( $44 \%$ and $56 \%$ respectively).

Unfortunately, this reduction in the number of mothers who failed to receive an injection was not reflected in the total number of new cases ( 49 in 1980 and 39 in 1985). This has led to a proportional increase in the number of mothers who developed antibodies in a subsequent pregnancy despite receiving an injection of anti-D immunoglobulin after the previous pregnancy (failures of protection).

I believe that this continuing incidence of failure of protection is due not to the injection of insufficient anti-D immunoglobulin but to intrapregnancy sensitisation. In our recently published study, quoted by Dr Hussey, 64 out of 163 new cases developed anti-D between 30 and 40 weeks' gestation $(40 \%)$, and these women cannot be protected by any dose of anti-D immunoglobulin given after delivery. Antenatal prophylaxis is the only procedure available at present to protect these mothers. Regional Transfusion Centre,

L A DERRICK TOVEY

1 Tovey LAD. Haemolytic disease of the newborn-the changing scene. Brf Obstet Gynaecol 1986;93:960-6.

Rh haemolytic disease of the newborn caused by anti-D antibodies in Yorkshire region 1980-5. Values in parentheses are percentages of new cases

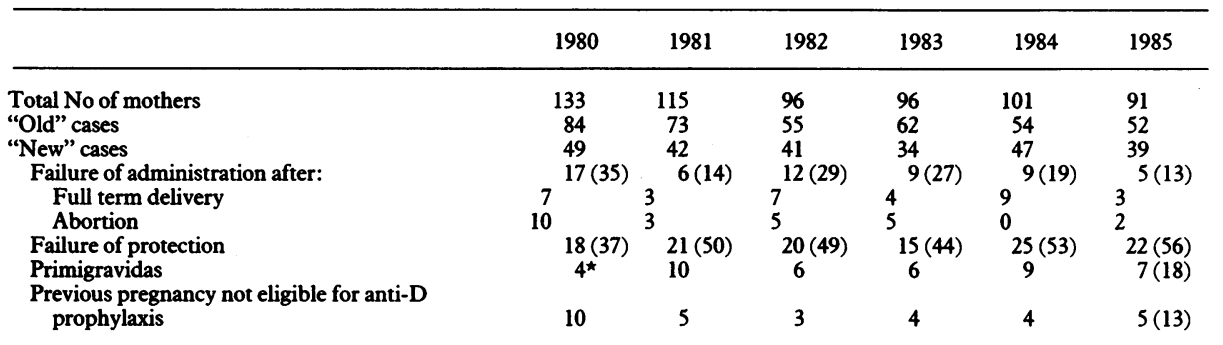

$\star$ Yorkshire antenatal trial.

\section{Early emergency care}

SIR,-Mr I W R Anderson and colleagues (24 January, $\mathrm{p} 228$ ) conclude that in the areas studied (Edinburgh and Glasgow) extended training of ambulancemen may not be justified because a group of assessors conducting a table top theoretical exercise could detect only 54 patients in a year who might have been saved by the skills related to such training.

Ignoring the abundant evidence from the United States and elsewhere in favour of extended ambulance skills ${ }^{1-4}$ the authors claim that there are limited data to support such training over and above basic ambulance aid. This completely contradicts reports based on hard data from centres that have had years of experience with ambulancemen trained to paramedic level. The two major cities in Scotland have no such first hand experience.

There is clear evidence, for instance, that early defibrillation by ambulancemen considerably reduces mortality from ventricular fibrillation ${ }^{13}$ and that early endotracheal intubation reduces mortality from pulmonary aspiration in cardiac arrest and severe acute overdose and head injury. ${ }^{1}$

We doubt very much whether the absence of such skills would be tolerated within the hospitals of Glasgow and Edinburgh. Why are they then not advocated during the prehospital phase of treatment in the same patient, when the equipment can be made available and the skills can be taught to the ambulancemen and women?

The authors quote a large number of patients admitted to their study as emergency cases (20 734), but only 1185 were classed as needing resuscitation presumably a sizable proportion of the total were patients referred by general practitioners who may well not have required even basic ambulance aidfor example, those with suspected appendicitis. Of the 1185 patients requiring resuscitation the assessors looked at 396 who died. Fifty of these were cases of trauma and 346 were medical emergencies. They concluded that "only 54 " might have been saved by extended skills applied before the patients reached hospital. This represents $13.6 \%$ of the total who died and, translated into a UK population of 50 million, would mean over 2500 lives saved each year (equivalent to about half of all the deaths due to road accidents)

We also find it hard to believe that in Edinburgh and Glasgow no one with severe asthma would have been rescued by the use of a nebuliser, no one saved by having a tension pneumothorax relieved, and only one with abdominal, pelvic, or limb blood loss who might have been resuscitated by a medical anti-shock garment.

By their own admission, the authors take no account of the effect of extended training on morbidity-without doubt an area of benefit of good training in any branch of medicine. The journey times of the ambulances in these cities (mean 30.3 minutes) leave something to be desired, 